\title{
openheart Arm exercise stress testing: diagnostic options in stable coronary artery disease
}

\author{
Rahul Bahl, ${ }^{1,2,3}$ Pascal Meierl ${ }^{1,2,3}$
}

To cite: Bahl R, Meierl P. Arm exercise stress testing: diagnostic options in stable coronary artery disease. Open Heart 2016;3:e000461. doi:10.1136/openhrt-2016000461

Accepted 22 April 2016

\section{SLinked}

- http://dx.doi.org/10. 1136/openhrt-2015-000333

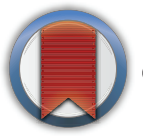

CrossMark

${ }^{1}$ Oxford University Hospitals NHS Foundation Trust, UK ${ }^{2}$ University College London, UCL, London, UK

${ }^{3}$ University of Geneva,

Geneva, Switzerland

Correspondence to

Dr Rahul Bahl;

rahulbahl2004@hotmail.com
Diagnostic and prognostic testing in coronary artery disease (CAD) is a rapidly expanding field and now includes a range of functional tests, imaging modalities and combinations of the two (stress imaging). For patients suspected of having occlusive $\mathrm{CAD}$, current European Society of Cardiology and National Institute for Health and Clinical Excellence guidance $^{12}$ recommends an approach where the probability of obstructive disease and the risk of future events are estimated to determine the next steps. Those at low-risk on the basis of history, examination and basic investigations do not need further assessment, while those at high-risk can proceed directly to treatment, including invasive angiography, if needed. However, for intermediate risk patients, there are a number of options.

Ideally, investigations for this population should be non-invasive, acceptable and applicable to a wide patient population and affordable for the health service. It should perform well enough to exclude the diagnosis while stratifying the risk of future events in those with occlusive $\mathrm{CAD}$, so providing a guide to future medical or interventional management. None of the currently available options tick every box and a tailored approach is needed for each patient. CT coronary angiography performs well but exposes the patient to ionising radiation and nephrotoxic contrast agents. Stress imaging can be carried out using echocardiography, MRI, positron emission topography or single photon emission CT (SPECT), and can utilise either physiological exercise or pharmacological agents as the stressor. However, often, these tests are expensive, time-consuming, and require highly qualified staff to perform and interpret. Exercise ECG testing is widely available, non-invasive and relatively simple to perform, but can be difficult or impossible to read in those with resting ECG abnormalities. In addition, those who are unable to perform exercise on a bike or treadmill are currently excluded from this test.
Xie $e t a l^{3}$ recognised that a large proportion of patients referred for stress testing were unable to perform the required exercise for the test due to common comorbidities such as peripheral vascular disease and arthritis. In a previous paper ${ }^{4}$ they demonstrated that, in this population, measures derived from arm exercise ECG stress testing (figure 1) were a feasible alternative to physiological and pharmacological stress imaging with SPECT. In the current paper, published in Open Heart, they used the same retrospective cohort to produce a risk stratification score analogous to that commonly used for treadmill stress testing. The equations produced, incorporating arm exercise capacity, $1 \mathrm{~min}$ heart rate recovery and ST segment depression $\geq 1 \mathrm{~mm}$, perform well in predicting future cardiovascular events, cardiovascular mortality and total mortality, especially once adjusted to account for common adverse clinical characteristics.

Some limitations of the study should be acknowledged. The cohort examined had a markedly high mortality rate $(27.1 \%$ at 5 years and $57.8 \%$ at 12 years) reflecting a very highrisk for adverse events. Current approaches tend to use stress ECG tests in patients with lower pretest probability of occlusive CAD, meaning that the performance of the test may not be as good in the population it is to be applied in. Against this, the higher mortality likely reflects the additional burden of

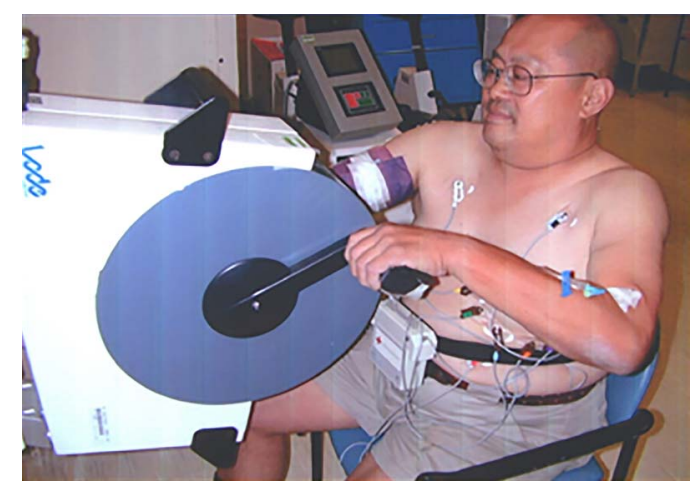

Figure 1 A patient performing arm exercise stress testing. 
comorbidity in this patient group and this would still be the case in clinical practice.

Another consideration is where to place arm exercise stress testing among the plethora of diagnostic options available, especially as existing guidance favours a stress-imaging approach even in low-intermediate probability patients. Despite this, there are some situations where the stress ECG option proves useful. Cardiologists are considering treatment options for an increasing number of patients with multiple comorbidities, ${ }^{5-7}$ including those that limit mobility. Stress ECG testing is a viable option to confirm diagnosis in such patients who would not be suitable for or would not want invasive management of CAD, so reducing the need for functional imaging. Those who have diagnosis confirmed derive substantial symptomatic and prognostic benefit from medical therapy while those who have occlusive CAD excluded are spared the side effects and risks of polypharmacy. It is also important to remember that, even if management stays the same, diagnostic and prognostic information can still be useful for patients and their relatives.

Finally, the current study is retrospective and the scores created need refinement and validation using randomised, prospective data. Ideally, this work should also incorporate measures to consider patient acceptability of the test and health economic evaluation.

Patient consent Obtained.

Competing interests None declared.
Provenance and peer review Commissioned; internally peer reviewed.

Open Access This is an Open Access article distributed in accordance with the Creative Commons Attribution Non Commercial (CC BY-NC 4.0) license, which permits others to distribute, remix, adapt, build upon this work noncommercially, and license their derivative works on different terms, provided the original work is properly cited and the use is non-commercial. See: http:// creativecommons.org/licenses/by-nc/4.0/

\section{REFERENCES}

1. Montalescot G, Sechtem U, Achenbach S, et al. 2013 ESC guidelines on the management of stable coronary artery disease: the Task Force on the management of stable coronary artery disease of the European Society of Cardiology. Eur Heart $J$ 2013;34:2949-3003.

2. Skinner JS, Smeeth L, Kendall JM, et al. NICE guidance. Chest pain of recent onset: assessment and diagnosis of recent onset chest pain or discomfort of suspected cardiac origin. Heart 2010;96:974-8.

3. Xie $\mathrm{Y}$, Xian $\mathrm{H}$, Chandiramani $\mathrm{P}$, et al. A prognostic scoring system for arm exercise stress testing. Open Heart 2016;3:e000333.

4. Martin $\mathrm{WH}$, Xian $\mathrm{H}$, Wagner $\mathrm{D}$, et al. Arm exercise as an alternative to pharmacologic stress testing: arm exercise stress testing and outcome. Am Heart J 2014;167:169-77.

5. Afilalo J, Mottillo S, Eisenberg MJ, et al. Addition of frailty and disability to cardiac surgery risk scores identifies elderly patients at high risk of mortality or major morbidity. Circ Cardiovasc Qual Outcomes 2012;5:222-8.

6. Arnett DK, Goodman RA, Halperin JL, et al. AHA/ACC/HHS strategies to enhance application of clinical practice guidelines in patients with cardiovascular disease and comorbid conditions: from the American Heart Association, American College of Cardiology, and U.S. Department of Health and Human Services. J Am Coll Cardiol 2014;64:1851-6.

7. Schmidt M, Jacobsen JB, Lash TL, et al. 25year trends in first time hospitalisation for acute myocardial infarction, subsequent short and long term mortality, and the prognostic impact of sex and comorbidity: a Danish nationwide cohort study. BMJ 2012;344: e356. 
Bahl R, Meierl P. Arm exercise stress testing: diagnostic options in stable coronary artery disease. Open Heart 2016;3:e000461. doi:10.1136/openhrt-2016-000461

The name of the second author was published incorrectly. The correct name should be 'Pascal Meier'.

Open Heart 2016;3:e000461corr1. doi:10.1136/openhrt-2016-000461corr1

CrossMark 